\title{
ENFOQUE MODULAR TRANSFORMACIONAL ${ }^{1}$
}

\author{
MODULAR TRANSFORMATIONAL SYSTEM
}

\author{
Emilce Dío Bleichmar ${ }^{2}$ \\ Universidad Pontificia Comillas, España
}

Palabras Clave: sistema modular transformacional; motivaciones; organización del psiquismo

Key Words: Modular Transformational System; human motivations; psychic organization

El objetivo de esta exposición será compartir los principios básicos del Enfoque Modular Transformacional así como su utilidad clínica.

Inspirados en el trabajo de Chomsky respecto a la modularidad de la mente, aplicamos su conceptualización al estudio de diferentes motivaciones que mueven a los seres humanos. Estas motivaciones que también se podrían entender como núcleos modulares, como módulos, como sistemas incluyen: la necesidad y el deseo de autoconservaciónheteroconservación; apego; satisfacción sexual/sensual; regulación psicobiológica y el logro de suministros narcisistas.

Este modelo del psiquismo está basado en la articulación de componentes y de sistemas motivacionales, es decir, módulos que pueden describirse por la cualidad de los deseos que activan y por las estructuras que implican.

Cada sistema motivacional tiene sus propias leyes organizativas y funciones por separado. Los sistemas entran en relación los unos con los otros y ejercen influencias recíprocas.

Pueden adquirir un valor diferente en cada individuo y su importancia puede variar en diferentes épocas de la vida. El predominio de aspectos de los varios sistemas motivacionales define una estructura de personalidad y por tanto, el enfoque técnico más apropiado para realizar una intervención.

La modularidad se refiere, en primer lugar, al cerebro e incluye la multiplicidad de motivaciones que se constituyen en sistemas, o sea en un conjunto de características y propiedades basados no solamente en la descripción psicológica, sino también en la activación de diferentes zonas cerebrales que determinarán los distintos sistemas motivacionales. Por lo tanto, las motivaciones corresponden a distintos módulos cerebrales. En la actualidad, la relación mente-cerebro es foco de investigación más profunda y no hay duda de que todo eso que vivimos y sentimos está vinculado a nuestro cerebro, y lo que ahora se está tratando de establecer es cuáles y cómo son las relaciones.

Eso que Freud llama "motor", que es el deseo y que le da a la líbido un carácter único, hoy en día podemos llamarlo "motivación". Desde el punto de vista neurocientífico se habla de activación cerebral; por lo tanto la motivación siempre tiene que ver con aquello que se pone en marcha y que en el modelo modular está determinada por el conjunto de las cinco motivaciones antes mencionados.

Ahora bien, estos circuitos dependientes y con propiedades de procesamiento diferente, que son los módulos cerebrales, pueden comprenderse más fácilmente haciendo un paralelismo con los programas de informática. Un programa es un subsistema de datos que procesa y acumula información y solamente puede obtener conclusiones a partir de los datos ingresados. Los datos de otro programa se pueden articular, lo cual supone la creación de un nuevo programa. Cada módulo y cada sistema motivacional, lo podemos entender así, como una base de datos específicos, con una metodología propia para cada circuito. Estos circuitos cerebrales se activan, se desactivan, se conectan y en este caso las interacciones entre los distintos sistemas motivacionales y los distintos circuitos cerebrales se dan naturalmente.

Ahora bien, esta interacción puede ser de sinergia, de potenciación, o puede suceder 
que un sistema invada el psiquismo y de esa forma inhiba el funcionamiento de otro de los sistemas. Un módulo, por ejemplo, el del narcisismo, busca su satisfacción a través del aumento de la autoestima, con lo que seguramente logrará aumentar la sensación de fuerza y poder para el individuo. Esto sin duda está involucrando al sistema de la autoconservación, por ejemplo; allí habría sinergia entre estos dos sistemas.

En cambio, por ejemplo, en el caso de los individuos que sufren un trastorno limítrofe de la personalidad, se genera un rechazo al contacto y a la relación, justamente por la ansiedad que genera el relacionamiento. Esto sin duda que afecta el sistema de apego y el sujeto se aparta o destruye aquello que más necesita para armar una imagen de sí consistente. En este caso el sistema del narcisismo y el del apego lejos de fortalecerse mutuamente se inhiben.

Es por esto que resulta muy importante estudiar, por un lado cada sistema, y por otro analizar la totalidad de estos así como sus interrelaciones, de forma de poder intervenir de una forma efectiva a nivel psicoterapéutico.

Vayamos entonces ahora al concepto de motivación. Para comenzar planteamos que no podemos reducir las motivaciones a dos, como lo hacía Freud, (sexualidad y autoconservación, o más adelante pulsión de vida y pulsión de muerte). En realidad las motivaciones son diversas y a la vez que se originan afectan diferentes aspectos del individuo. Dentro del Psicoanálisis fue Kohut quien amplió la concepción freudiana al establecer al narcisismo como un sistema propio, positivo e imprescindible para el ser humano y que está más allá de la búsqueda sexual o de la necesidad de cuidados para la supervivencia. El postuló que el ser humano necesita un grado de autoreconocimiento y de amor a sí mismo al momento de sostener cualquier tarea. El narcisismo aparece entonces como un nuevo sistema motivacional específico, también con base genética, como la sexualidad y la autoconservación.

Otra motivación de gran importancia postulada por el psicoanálisis contemporáneo es la regulación tanto emocional como psicobiológica. Está presente en el inicio de la vida y podemos rastrear ya desde la vida intrauterina una búsqueda de regulación del medio para po- der sobrevivir en él. Aquí estaríamos hablando en términos exclusivamente fisiológicos y quisiéramos agregar que esta búsqueda instintiva se va transformando hasta configurar una búsqueda pulsional. Freud utiliza el concepto de pulsión para describir el trabajo que a la mente le impone el cuerpo. Y esto sería la pulsión, que en eso se diferencia del instinto: la pulsión es el movimiento psíquico que tiene su origen en el cerebro (mente, al decir de Freud) para regular el cuerpo. Esta interrelación se pone claramente de manifiesto en las emociones primarias, a las que no podemos considerar como contenidos mentales, sino como estados fisiológicos significados por la mente/cerebro.

La regulación psicobiológica será entonces una motivación básica de gran importancia en la construcción del mundo representacional del individuo. Por otro lado, la regulación emocional será entonces la capacidad para mantener tanto un estado óptimo de activación del sistema nervioso, como del desarrollo y la expresión de los afectos.

Las motivaciones constituyen entonces estados internos, deseos, fantasías, pensamientos que buscan conducirnos hacia determinado fin. Pero también en algunos enfoques la motivación tiene que ver con un estímulo externo, o sea con algo que despierta la acción desde afuera y tal es el caso de la mente de los cuidadores, que al interactuar con el niño pequeño trasmiten sus propios deseos, sus propias motivaciones y de esa forma van generando en el niño una suerte de motivación. Así comienza la historia, que luego vamos procesando hasta llegar a construir nuestro propio sistema motivacional, que será el resultado de lo que recibimos, más lo que realmente trajimos nosotros mismos al nacer (temperamento, constitución), atravesado por las circunstancias de vida. La influencia o la interacción de los otros, de las figuras de apego tempranas, de la familia, del medio social, configuran las motivaciones que sostienen nuestra identidad y nuestra sensibilidad y que así como nos caracterizan nos diferencian de todos los demás. Yo y no yo se van así conformando.

Dentro de estos planteos consideramos que la intersubjetividad y la interacción son la base del desarrollo humano, del psiquismo, de las motivaciones, de los sistemas; en definitiva, de la subjetividad. Por ello resulta muy grave que el sujeto no pueda relacionarse, interactuar, 
ser cuidado y cuidar, ya que el psicoanálisis contemporáneo sostiene que la subjetividad sólo se construye en relación a y con otro. Así como nacemos prematuros desde el punto de vista fisiológico también nacemos prematuros psicológicamente, lo cual modifica sustancialmente los planteos por ejemplo de M. Klein, quien sostenía que el ser humano ya nace con capacidad de introyectar y proyectar, de crear símbolos.

Queremos entonces destacar que son estos los tres aspectos primordiales en los que se basa nuestro enfoque modular: modularidad del cerebro, multiplicidad de motivaciones y modelo relacional del desarrollo.

A su vez, sostenemos que cada sistema motivacional se va transformando a lo largo de toda la vida y es justamente eso lo que nos habilita a intervenir en los ciclos de transformación y por medio de una psicoterapia. Las capacidades de parentalización, las capacidades de los cuidadores van a estar también en el foco de la intervención, para lograr una transformación a nivel clínico. Así es como se va gestando lo que llamamos transmisión intergeneracional y en la que se sostiene la idea de que hay una forma de herencia psicológica, similar a la herencia genética, que tiene que ver con la intimidad de la relación de desarrollo que crea las condiciones de la subjetividad y que se va trasmitiendo de generación en generación tanto de forma consciente como inconsciente ya que no somos siempre conscientes de lo implícito de nuestra conducta, de los gestos, de aquello que transmitimos y no nos damos cuenta y que inclusive en ocasiones no reconocemos. Todo este proceso podría ser también reproducido en la psicoterapia dentro del vínculo con el psicoterapeuta. Nos estamos refiriendo al vínculo de apego necesario, es decir a la búsqueda de una base segura que nos de la posibilidad de sentirnos valiosos, seguros y en función de ello más autónomos.

Pensemos ahora en la sexualidad. El sistema motivacional de la sexualidad, el núcleo inicial del psicoanálisis: la teoría de la libido. Seguramente habrán escuchado y aprendido las fases de la sexualidad: la oral, anal, latencia, fálica y genital. Esta es una descripción de la sexualidad casi endogenista, algo que le sucede al niño a medida que va teniendo más edad. En la actualidad, esta teoría está orientada a destacar el valor de la sensua- lidad y no solamente de la sexualidad. Una madre, una abuela o quien sea que tenga en brazos a un bebé, ya sea para darle la teta o la mamadera, establece con él un contacto cuerpo a cuerpo, que es muy importante en la primera infancia, y que despierta los sentidos, es decir, que activa la sensorialidad; activa el tacto, activa la temperatura, activa la mirada, escucha la voz. Intervienen todos los sentidos. La sensorialidad en pleno es el canal de comunicación temprana entre la madre y el bebé, y son los sentidos los que van creando una familiaridad en el contacto que luego integrará la organización de esa personalidad. Por ejemplo uno puede escuchar una voz, y le produce placer, o puede escuchar una voz y sentir rechazo o displacer. Uno puede tener contacto con una piel, y eso generarle una sensación de suavidad, de ternura, o uno puede tener un contacto con una piel que le resulta molesta, que genera displacer. Por lo tanto, el tema del contacto cuerpo a cuerpo a través de los sentidos, es el que puede generar el placer que llamamos sensual. No sexual, sino sensual. El placer sensual es el placer de los sentidos, es el placer de la música, de la danza, del perfume, de la caricia. Esa es la sensualidad, y esto es lo que se da básicamente entre la madre y el bebé. Esto en el psicoanálisis clásico no aparece así sino como sexualidad oral. Lo tradicional es que se le llame a todo sexualidad y que no se diferencie la cualidad sensorial sensual.

Hay sexualidad cuando el bebé tiene una erección, si es un bebé varón, y hay sexualidad cuando la nena aprieta las piernas o contiene una forma de estimulación de su clítoris o sus genitales. Esto cualquier bebé lo experimenta, por ejemplo, cuando lo cambian o lo bañan, porque es en esos momentos cuando sus zonas sexuales se estimulan y surge la motivación con la activación de una zona del cerebro. Los cuidados higiénicos, que son absolutamente normales y desarrollados por todas las madres, activan muy puntualmente, a veces, la sexualidad del infante. Pero lo que la relación cuerpo a cuerpo, y la relación de cuidados del adulto activa permanentemente es la sensorialidad y la sensualidad. De esto es lo que carecen los niños criados en instituciones, donde básicamente se carece de todo lo que tiene que ver con la sensualidad; porque no hay nadie que se relacione con el cuerpo 
del niño de una forma amorosa. Laplanche, psicoanalista francés presenta sus estudios al respecto a través de lo que él llamó la Teoría de la Seducción Generalizada, en la que sostiene que el adulto "seduce" de una manera natural al bebé; no es que desee abusar de él, sino que en el contacto naturalmente activa su sensualidad y su sexualidad, lo cual es absolutamente diferente a cuando el adulto tiene la intencionalidad de excitar al bebé o al niño, provocando su propia excitación. Esto es muy diferente a cuando se da esto sin ninguna intencionalidad abusiva, por el contacto del cuidado amoroso.

Es a partir de la teoría de Laplanche que el psicoanálisis considera que el sistema sensual-sexual se activa, se estructura y se desarrolla en parte por la influencia y la activación del adulto. Y aquí tiene muchísima importancia justamente la conducta de los adultos, no solamente en relación al niño y desde el punto de visto de la activación de la sexualidad, sino del escenario sexual que atestigua el niño. Escenario sexual constituido ya no solamente por la escena primaria o la fantasía de las relaciones sexuales entre los padres, sino todo lo que tiene que ver con las particularidades o peculiaridades de las formas y las modalidades que tienen los adultos de mostrarse en actitudes o de mostrar su deseo sexual o no. Eso que muchas veces se escucha en las sesiones clínicas de adultos, que dicen: "yo nunca vi a mis padres darse un beso" o "permanentemente los vi, vi a mi madre o a mi padre con miradas sexuales". El tema de las miradas es algo muy importante, que los niños captan. Se estimulan o se asustan de esto, y también hay que tenerlo muy en cuenta en la clínica. Entonces fíjense cómo los sistemas motivacionales se configuran en torno al conocimiento que tengamos también de las características de los adultos que nos cuidan y de sus propias motivaciones.

Volvamos ahora a un sistema al que ya nos hemos referido : el del narcisismo. Kohut planteaba que todo niño necesita ser idealizado, constituirse al decir de Freud como "su majestad el bebé"; sentir que es alguien muy importante para los padres, que los padres lo admiran. O sea que la admiración por un hijo es durante una fase del desarrollo muy buena y en eso se apoya la autoestima, dándole al niño un sentimiento de poder. Se es poderoso porque se despierta la admiración de los padres; esto es el núcleo de una buena autoesti- ma, aunque por supuesto deba transformarse posteriormente. Por otro lado el niño tiene que poder tener la experiencia de poder admirar a sus padres. Generalmente todo niño pequeño admira a sus padres, porque los ve fuertes, porque los ve grandes, porque los ve capaces de hacer todo aquello que él no puede, pero esto tiene que mantenerse en el tiempo como un sentimiento sólido de que los padres son sujetos con cierto poder. Cuando esto falta, ya sea porque no hay padres, o porque los padres no admiran al niño, o porque los padres efectivamente ejercen su paternidad o maternidad de manera muy defectuosa, el problema mayor no solamente tiene que ver con el establecimiento del vínculo sino con el soporte de su autoestima que se evidenciará de forma diferente dependiendo de qué otro sistema motivacional quede afectado. Si es el sistema de apego, por ejemplo, entonces el sujeto se sentirá muy inseguro y temerá todo el tiempo ser abandonado, si es el sistema sensual/sexual, entonces considerará que no puede lograr que lo quieran tiernamente o que lo deseen sexualmente.

Vemos entonces que lo relacional, lo intersubjetivo afecta el apego, la sexualidad/sensualidad, el narcisismo; relacionemoslo ahora con la regulación emocional. Imaginemos alguien que se siente invadido por la tormenta emocional de un adulto cuidador que grita, gesticula y se mueve sin poder controlarse. El niño puede inhibirse, irse a un rincón, tratar de no ser invadido; o por el contrario magnificar su temor y gritar, llorar, atraer sobre sí la atención, como reacción tal vez a la hiperemocionalidad de quien lo cuida. Y si este cuidador no logra comprender lo que el niño está expresando y por qué, en consecuencia, espejarlo, otorgándole un significando a su emoción, entonces el niño no aprenderá a regular sus emociones.

Concluimos así que el modelo presenta una propuesta de complejidad. Las motivaciones son diversas (nosotros solamente destacamos la autoconservación, el apego, la regulación emocional, el narcisismo y la sensualidad/sexualidad). Cada motivación se va construyendo y organizando sobre la base de lo constitucional, lo ambiental y fundamentalmente en lo intersubjetivo. Es a través de su consideración y análisis como podremos orientarnos hacia aquellos aspectos del individuo sobre los que podremos trabajar para aumentar su bienestar. 
${ }^{1}$ Conferencia dictada por la Prof. Dra. Emilce Dio Bleichmar como introducción al Seminario de Psicopatología, dictado dentro del programa de la Maestría en Psicología Clínica del Niño y del Adolescente, de la Facultad de Psicologia de la Universidad Católica del Uruguay. Setiembre 2014.

${ }^{2}$ Doctora en Medicina, Universidad de Buenos Aires, Universidad Autónoma de Madrid.

Directora Académica y Profesora de Postgrado de la Universidad Pontificia Comillas y de la Universidad Universidad Complutense de Madrid.

Miembro de la Asociación Psicoanalítica Argentina (IPA), de la Red Internacional del Apego (IAN) y de The International Asociation for relational Psychoanalysis and Psychotherapy (IARPP).

Para citar esta Conferencia:

Bleichmar, E. (2015). Enfoque Modular Transformacional. Ciencias Psicológicas 9(2): 197 - 201 